\title{
Quality Analysis and Quantum Classical Analysis of Acetaminophen
}

\author{
Naidu Dhanpal Jayram, T. Santosh, S. Jeyavijayan, M. S. Revathy, S. Sonia
}

\begin{abstract}
In recent year's Raman and IR spectroscopy has been widely used by pharmaceutical industry as a analytical tool for quality control. The present work Acetaminophen (common name paracetamol) is been characterized using Raman, FTIR, and $U V$-visible techniques. 5 different brands of tablets (name changed as $A, B, C, D$, and $E$ ) purchased from Medical shop for analysis and comparative studies. Spectrum recorded using Raman shows major peak in between $400-1600 \mathrm{~cm}-1$ wavelength respectively; the Y-axis intensity for them varies along shift in $x$-axis but majorly all remains same except in Tablet $C$. FTIR spectroscopy doesn't show much variation in the reflectance spectra but slight variation in y-axis intensity is noted. $U V$-visible remains same for all the tablets. For comparison the optimized geometries, harmonic vibrational wave numbers and intensities of vibrational bands of Acetamenophen were determined using DFT-B3LYP with 6-311++G(d,p) level calculations. Weight variation and Tablet disintegration studies were also done to confirm weight in gms of individual tablet. The disintegration time shows breaking of tablets particles into smaller ones in particular time. The analysis of paracetomol quantity and its interdependence on the optical characterization such as Raman, FTIR, were interpreted through means of band width; functional group and bond length. UV-visible spectroscopy helps to determine the volumetric concentration dependence on functional group. The theoretical calculations were matched with experimental results.
\end{abstract}

Keywords :Acetaminophen; FTIR; FT-Raman; DFT, weight variation and Tablet disintegration

\section{INTRODUCTION}

Para-Acetaminophen commonly known as Paracetamol is an active form of Phenacitin[1-4]. This Para-Acetaminophen is used widely as an antipyretic and analgesic drug. Acetaminophen is 4 hydroxy acetanilide chemically consists of hydroxyl, carboxyl and nitrogen shown in Fig.1.Acetaminophen (Paracetamol) is generally available as a tablet for adults and syrup based fluid for children. It comes under non-steroidal and anti-inflammatory drug by many sources. Acetaminophen shows some anti-inflammatory

Revised Manuscript Received on December 15, 2019

* Correspondence Author

Naidu Dhanpal Jayram*, Physics, Kalasalingam Academy of Research and Education, Krishnankoil, Virudhunagar, India. Email: dhanpal.dj@gmail.com

T. Santhosh, Physics, Kalasalingam Academy of Research and Education, Krishnankoil, Virudhunagar, India. Email:

S. Jeyaviajyan, Physics, Kalasalingam Academy of Research and Education, Krishnankoil,Virudhunagar, India.

Email: sjeyavijayan@gmail.com

M. S. Revathy,Physics, Kalasalingam Academy of Research and Education, Krishnankoil, Virudhunagar, India.

Email: revz.vijay@gmail.com

S. Sonia, Physics, Holy Cross College(Autonomus), Nagercoil, India. Email: sonianst10@gmail.com effect in comparison with other painkiller drugs. Acetaminophen is available in different dosages as Paracetamol tablets, capsules, syrup based and also suspension solution [8-10]. It is low-cost antipyretic and analgesic drug available in world market. It is readily available in all local stores as a handy drug to reduce fever. There are numerous manufacturer of acetaminophen drug. The preparation of drug varies according to the methods and employs. Paracetamol is mainly used to reduce fever and body pain for all ages [5-7]. It is used with other combinations to counteract cold and other flu. Usage of this drug provides nearly no side effects. Overdose of the drug may cause serious damage to the liver [11-13]. The lowest dose of the Paracetamol for adult is $7.5 \mathrm{~g} / \mathrm{kg}$ in adults and $150 \mathrm{mg}$ in children. Paracetamol overdose causes Hepatotoxicity, which leads to serious liver complications. It is the common poisoning worldwide. More amount of Paracetamol toxicity leads to hepatic encephalopathy. Increased amount of dosage can cause stomach bleeding. (Vidhya and bhai 2006). Other than liver, calcified kidney is the second victim of Paracetamol toxicity. (Beasley et al., 2008) [14-16]. Prolong usage of this acetaminophen will thin the blood and the blood would lose the ability to clot. To avoid all the side effects caused by Paracetamol we have to analyze the quality of the available drugs in the market. There are many certified manufacturers of these drugs are found in India. In the present work,five popular brands of acetamiphenon (named given as A, B, C, D, E) were recorded using Raman, FTIR, UV spectra respectively. The main purpose of the study is to find out the quality of the Paracetamol tablets by optical characterizations and quantity analysis through weight variation, dissolution test, and disintegration time.

\section{EXPERIMENTAL}

\section{A. Materials and Methods}

The comparison study with different brands of Paracetamol 500mg tablets showed notable results. Five different brands of Paracetamol tablets coded as A B C D E are tested using weight uniformity, disintegration time and dissolution test. The necessary data for a tablet sample are noted and the chemical composition mentioned in the Paracetamol tablet strip is noted. Only acetaminophen content in all of Paracetamol tablet brand strip is confirmed and noted.The expiry date is noted andtaken into consideration prior to two years from the date of manufacture. 


\section{Quality Analysis and Quantum Classical Analysis of Acetaminophen}

\section{B. Weight Variation}

Each tablet of different band is weighed using a digital balance. The weight of the tablet varies from brand to brand even it is formally advertised as $500 \mathrm{mg}$ of acetaminophen. The variation of weight in different tablet is very much important when dosage of the Paracetamol is concerned. This is one of the important test to test the amount of Paracetamol content is present in each tablet.

\section{Tablet Disintegration}

Disintegration time is defined as the breakup of particles into smaller ones in particular period. The breakdown of the larger particles into smaller particle is noted. To test for the disintegration of the tablet we have to put the tablet in a beaker containing $0.1 \mathrm{~N} \mathrm{HCl}$ acid at a temperature of $70 \mathrm{C}$ the beaker is then placed in a magnetic stirrer at a constant frequency. The disintegration time for each of the acetaminophenwere noted.

\section{FTIR}

FTIR is used to find infrared spectrum for solid, liquid or gas samples. Results for FTIR show the bonding between the molecules of the sample. It is the analysis of different compounds present in the material. FTIR gives peaks concerned to different bonding in the compound. The results are noted. Experimental datas were recorded using

\section{E. UV-absorption}

UV - absorption for wavelength of region is observed. The absorption peak gives suitable results in the form of graph.The results are noted.UV-Visible analysis was carried out using UV- Visible spectrometer (Jasco V-640).

\section{F.Raman}

The shift in energy gives information about the vibrational, rotational and other low frequency transitions present in the molecules.Raman spectrometer (LABRAM-HR) with laser excitation lines of 514 and $632 \mathrm{~nm}$ respectively at room temperature with power of $15 \mathrm{~mW}$ and acquisition of 6 seconds applied for the individual films.

\section{RESULT AND DISCUSSION}

\section{A. Molecular geometry}

The molecular structure of the Acetaminophen molecule was optimized using standard $6-311++G(d, p)$ basis set as shown in Fig.1. The global minimum energy of the optimized molecular structure of the molecule is calculated as -919.577287 and -919.709992 Hartrees respectively.

\section{Vibrational spectral analysis}

The Acetaminophen molecule contains 18 atoms and hence it has $48(3 \mathrm{~N}-6)$ normal modes of vibrations. The molecular geometry of the molecule possesses $\mathrm{C}_{1}$ point group symmetry and all the normal modes of vibrations are present in both infrared (IR) and Raman spectra. The observed FT-IR and FT-Raman spectra of Acetaminophen molecule are presented in Fig. 2. The calculated, observed vibrational frequencies, infrared intensity, Raman activity and vibrational assignments listed in Table 2 [16-18].In general, the calculated vibrational wavenumbers are usually higher than the corresponding experimental vibrational wavenumbers, which is due to the anharmonicity in the DFT calculations; basis set incompleteness and neglect of electron correlation. Therefore, in order to improve the calculated vibrational wavenumbers in agreement with the experimental ones, it is necessary to scale down the calculated harmonic frequencies. A better agreement between the computed and experimental vibrational frequencies can be obtained by using scale factor [19] of 0.96 for B3LYP method.

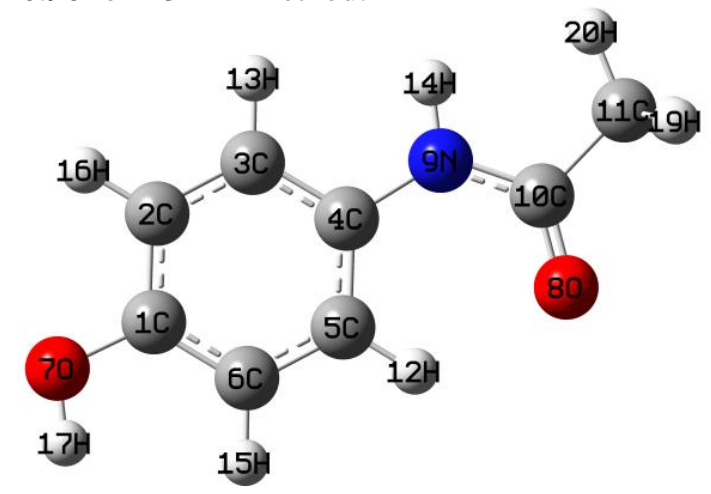

Fig.1. Molecular structure of Acetamiphenon

A better agreement between the computed and experimental frequencies can be obtained by using scale factor [19] of 0.96 for B3LYP method. The resultant scaled frequencies are also listed

\section{B. Mulliken charges analysis}

The calculation of atomic charges describes a significant task in the application of quantum mechanical calculations to molecular systems [19]. Mulliken population analysis has been carried out for the comparison of different choice of the basis sets to describe the electron distribution in CHAP. The Mulliken charges calculated at different basis set calculations are listed in Table 4. The carbon atom C2 has the high negative charge, atoms $\mathrm{C} 3$ and $\mathrm{C} 5$ have positive charges since they are attached with $\mathrm{OH}, \mathrm{CO}-\mathrm{CH}_{3}$ and $\mathrm{Cl}$ groups, respectively, which leads to redistribution of electron density. All the hydrogen atoms have a net positive charge because they are electron acceptors.

TABLE- I: Mulliken charges analysis for acetamiphenon

\begin{tabular}{|c|c|}
\hline Atoms & $\begin{array}{c}\text { Atomic charges } \\
\text { (Mulliken) }\end{array}$ \\
\hline C1 & -0.320 \\
\hline C2 & -0.256 \\
\hline C3 & -0.362 \\
\hline C4 & -0.354 \\
\hline C5 & 0.534 \\
\hline C6 & 0.009 \\
\hline O7 & -0.246 \\
\hline H8 & -0.346 \\
\hline C9 & -0.080 \\
\hline O10 & 0.358 \\
\hline C11 & -0.655 \\
\hline H12 & 0.246 \\
\hline H13 & 0.133 \\
\hline H14 & 0.255 \\
\hline H15 & 0.142 \\
\hline C116 & 0.194 \\
\hline H17 & 0.264 \\
\hline H18 & 0.183 \\
\hline
\end{tabular}




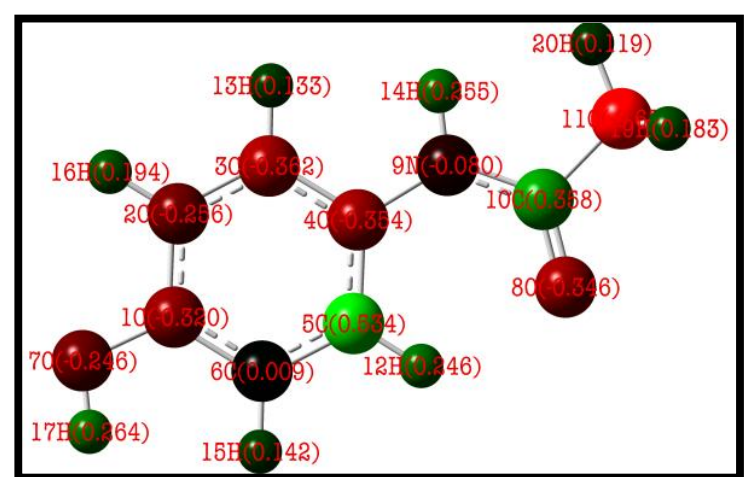

Fig. 2. The Mulliken atomic charge distribution of the paracetamol molecule.

\section{HOMO-LUMO analysis}

The frontier molecular orbitals (FMOs) such as highest occupied molecular orbital (HOMO) and lowest unoccupied molecular orbital (LUMO) play an important role in the electric and optical properties, as well as in UV-vis spectra and chemical reactions[20]. The HOMO-LUMO orbital for acetaminophen is shown in Fig. 3.In this study, the HOMO is located over ring system, hydroxyl, carbonyl groups and LUMO: of $\pi$ nature, (i.e. benzene ring) is delocalized over the whole $\mathrm{C}-\mathrm{C}$ bond of the ring; consequently the $\mathrm{HOMO} \rightarrow$ LUMO transition takes place to the $\mathrm{C}-\mathrm{C}$ bond of the benzene ringalong with $\mathrm{O}-\mathrm{H}$ and $\mathrm{C}=\mathrm{O}$ group.The HOMO-LUMO energy gap is found to be $3.59 \mathrm{eV}$ by B3LYP/6-311++G(d,p) method. This explains the ultimate charge transfer interaction within the molecule, which influences the biological activity of the molecule.

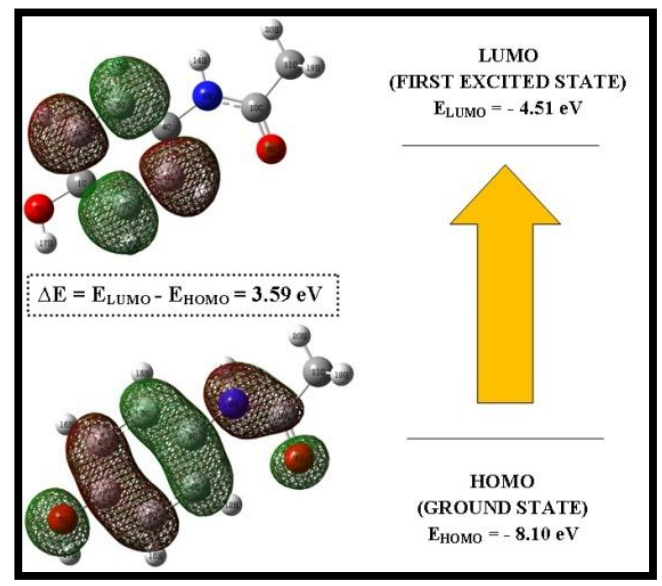

Fig.3. HOMO-LUMO for Acetamiphenon

\section{FTIR}

The tablets of brand A and brand D show sharp peaks of 1014 and 1015 in the FTIR resultant graphs. Nearly all the FTIR result for the bands shows similar results other than brand $\mathrm{A}$ and brand $\mathrm{D}$. The presence of strong $\mathrm{C}-\mathrm{N}$ stretch is observed in the Paracetamol compound of brand $\mathrm{A}$ and brand $\mathrm{D}$ infers the results from other brands of Paracetamol. The presence of 1600 peak on all the compounds of A, B, C, D, E resembles $\mathrm{C}=\mathrm{O}$ amide in stretch mode, $\mathrm{NH}$ bond and $\mathrm{CH}$ bond in differential manner [21]. Sharp peaks infer that the bonding is strong. The FTIR graph is shown in Fig. 4.
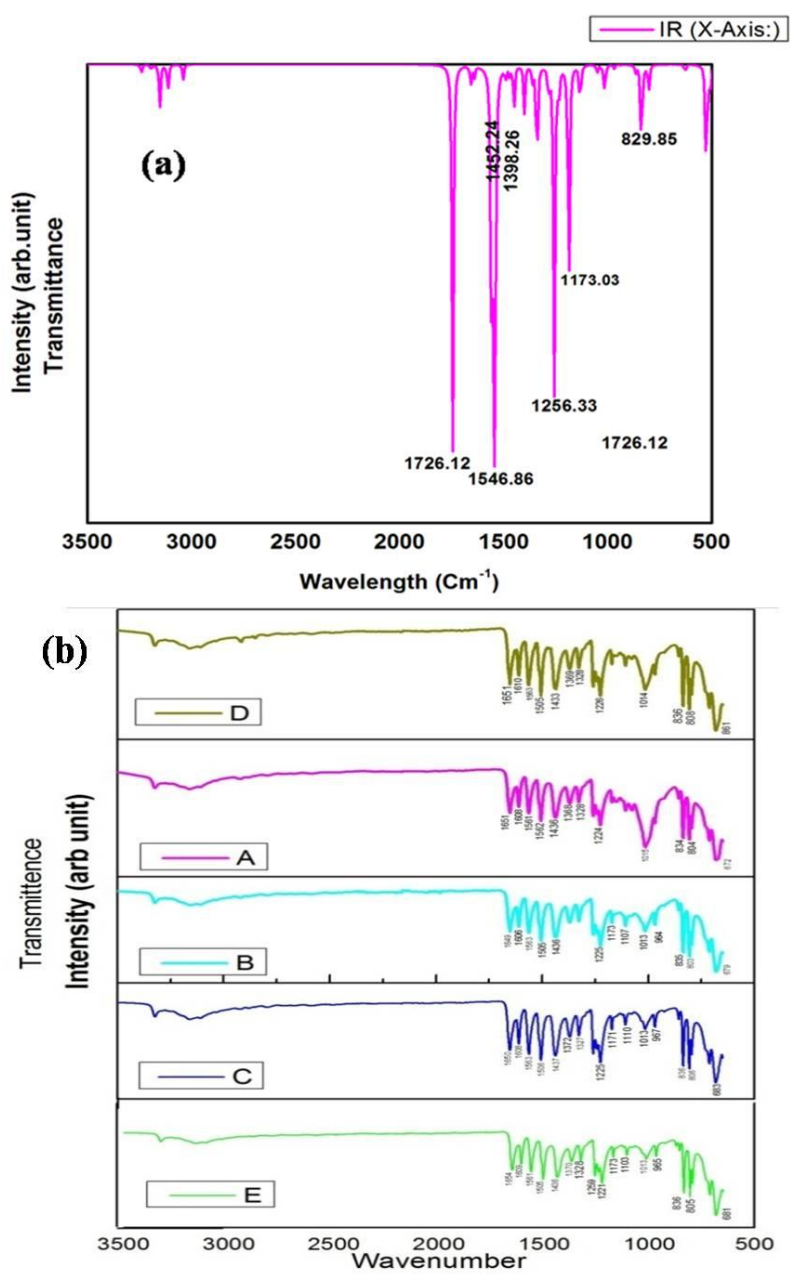

Fig.4. FTIR spectra Acetaminophen (a) spectra DFT-B3LYP (b) Experimental FTIR for 5 tablets

\section{E. Raman studies}

The Raman spectrum of acetaminophen is dominated by peaks at 797, 858, 1236, 1324, 1560, 1611, and $1649 \mathrm{~cm}^{-1}$, which are assigned to CNC ring stretching, ring breathing, $\mathrm{C}-\mathrm{C}$ ring stretching, amide III, amide II, ring stretching, and amide I modes, respectively [22] 


\section{Quality Analysis and Quantum Classical Analysis of Acetaminophen}

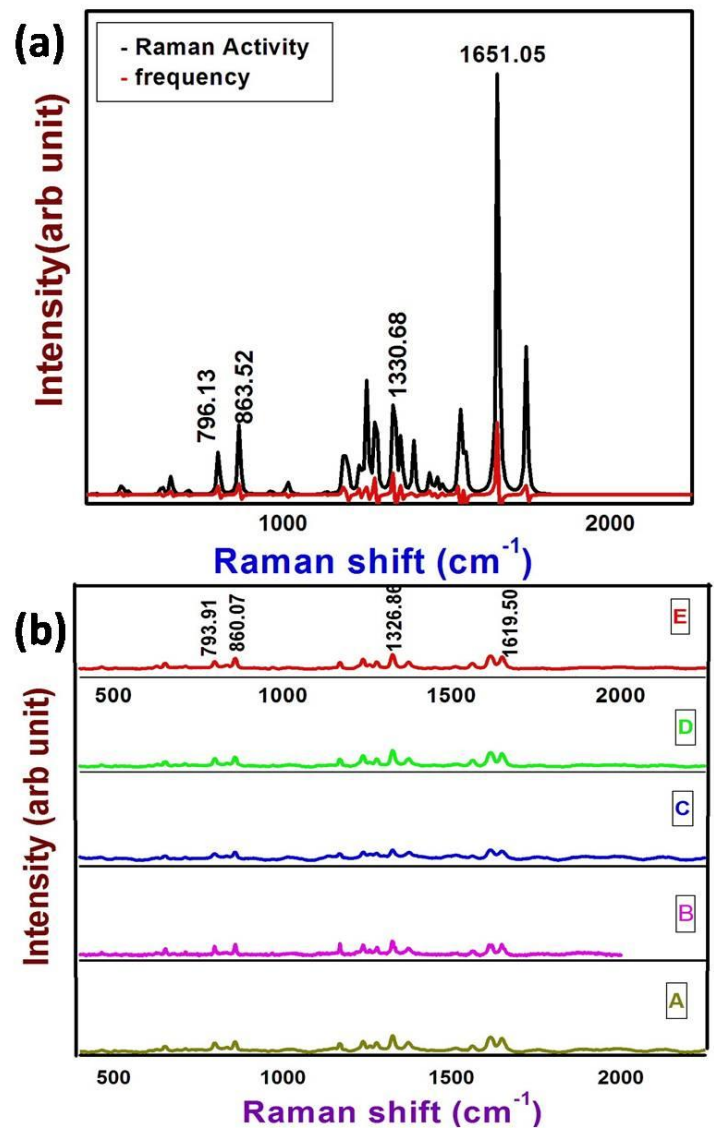

Fig. 5. Raman spectra for Acetaminophen (a) spectra DFT-B3LYP (b) Experimental Raman for 5 tablets

Table II. FTIR, Raman and vibrational frequencies $\left(\mathrm{cm}^{-1}\right)$ for Acetaminophen (a) Experimental (b) theoretical

\begin{tabular}{|c|c|c|c|c|c|}
\hline \multirow[t]{2}{*}{ No } & \multicolumn{2}{|c|}{$\begin{array}{l}\text { Experimental } \\
\text { frequencies }\end{array}$} & \multicolumn{3}{|c|}{ B3LYP 6-311++G(d,p) } \\
\hline & FTIR & $\begin{array}{c}\text { FT-Ra } \\
\text { man }\end{array}$ & $\begin{array}{c}\mathrm{IR} \\
\text { intensi } \\
\text { ty }\end{array}$ & $\begin{array}{l}\text { Raman } \\
\text { activity }\end{array}$ & Bonds \\
\hline 1 & & & $\begin{array}{c}1726 \\
.12\end{array}$ & $\begin{array}{c}1745.3 \\
7\end{array}$ & $\mathrm{C}=\mathrm{O}$ Stretching \\
\hline 2 & $\begin{array}{l}1651 \\
1610\end{array}$ & $\begin{array}{c}1619 \\
.50\end{array}$ & & 1651 & C-C Stretching \\
\hline 2 & $\begin{array}{l}1563 \\
1505\end{array}$ & $\begin{array}{c}1558 \\
.21\end{array}$ & $\begin{array}{c}1546 \\
.86\end{array}$ & 1543. & C-C Stretching \\
\hline 3 & 1433 & & $\begin{array}{c}1452 \\
.24\end{array}$ & 1444.58 & C-C Stretching \\
\hline 4 & $\begin{array}{l}1369 \\
1328\end{array}$ & $\begin{array}{c}1326 \\
.86 \\
1374 \\
.33\end{array}$ & $\begin{array}{c}1398 . \\
26\end{array}$ & $\begin{array}{c}1372.2 \\
5\end{array}$ & C-C Stretching \\
\hline 5 & 1226 & & $\begin{array}{c}1256 \\
.33\end{array}$ & $\begin{array}{c}1257.0 \\
6\end{array}$ & C-N Stretching \\
\hline 6 & & $\begin{array}{c}1162 \\
.05\end{array}$ & $\begin{array}{c}1173 \\
.03\end{array}$ & $\begin{array}{c}1179.9 \\
4\end{array}$ & $\begin{array}{l}\mathrm{C}-\mathrm{H} \text { in plane } \\
\text { bending }\end{array}$ \\
\hline 7 & $\begin{array}{l}836 \\
808 \\
861\end{array}$ & $\begin{array}{c}860 . \\
07\end{array}$ & $\begin{array}{c}829 . \\
85\end{array}$ & 863.02 & $\begin{array}{l}\mathrm{C}-\mathrm{H} \text { out of plane } \\
\text { bending }\end{array}$ \\
\hline & & $\begin{array}{c}793 . \\
91\end{array}$ & & & \\
\hline
\end{tabular}

Through the table 3 we can able to find that all the vibrational frequencies are well matching experimentally and theoretically, which shows that the quality of tablets are well matched and good.

\section{F. UV-absorption studies}

The maximum absorption is observed at the wavelength of $243 \mathrm{~nm}$ for all the tablet samples taken. Tablet sample B and $\mathrm{D}$ shows maximum value of $\sim 249 \mathrm{~nm}$. With the calculation of the Beer lamberts Law $\mathrm{A} \propto \varepsilon \mathrm{C}$. Where, $\mathrm{A}$ is the absorbance and $\mathrm{C}$ is the concentration of the sample.Hence, concentration is directly proportional to the absorbance peak [23]. Thus maximum absorbance peak (i.e. $243 \mathrm{~nm}$ ) will be $\lambda_{\max }$. The concentration of all samples remains nearly the same. Thus the concentrations of acetaminophen are same for all the brands of Paracetamol nearly. The UV-Absorbance graph is shown in Fig.5.
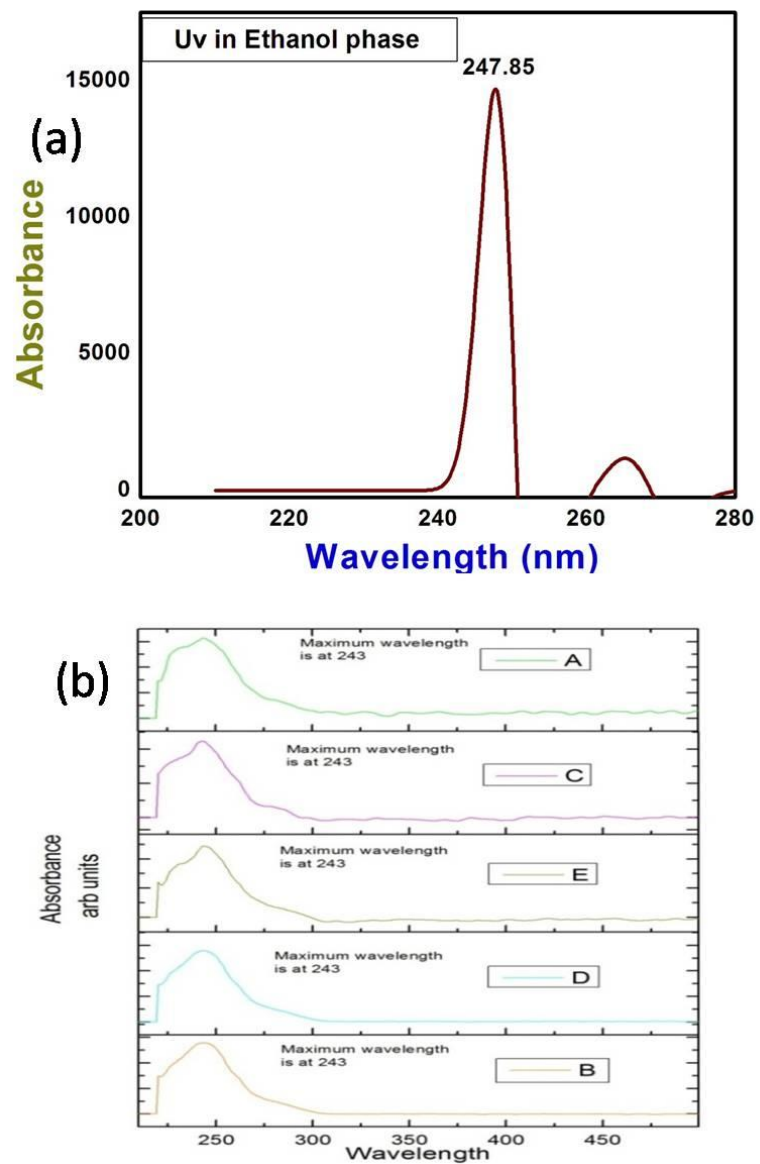

Fig. 6. UV-vis spectra for Acetaminophen (a) spectra DFT-B3LYP (b) Experimental Uv-Vis for 5 tablets

\section{QUANTITATIVE ANALYSIS}

\section{A. Weight Variation}

Each tablet of different band is weighed using a digital balance. The weight of the tablet varies from brand to brand even it is formally advertised as $500 \mathrm{mg}$ of acetaminophen. The results are tabulated below in Table- II. The weight variation is also graphically represented in Fig. 2. 
Table- II: Different wt in gms for tablets

\begin{tabular}{|c|c|}
\hline Tablet & Weight in gms \\
\hline A & 0.5870 \\
\hline B & 0.5878 \\
\hline C & 0.6282 \\
\hline D & 0.5850 \\
\hline E & 0.6172 \\
\hline
\end{tabular}

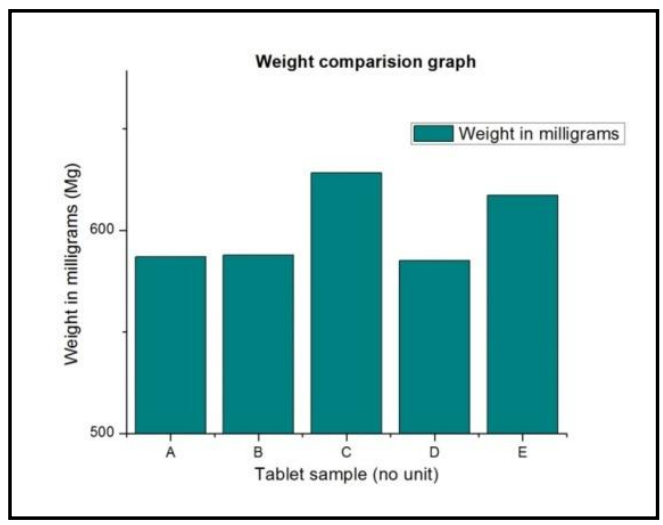

Fig. 7. The weight variation

\section{B. Tablet Disintegration}

Tablets of Acetaminophen disintegrated in the self-made solution of 0.1 Normal Hydrochloric acid in variable time ranging from seconds to minutes. Higher the Disintegration time greater is the tablet dissolves. Table- III shows variable results. Thus immediate action and side effects are more in tablets which have higher disintegration time. The tablet sample A has lowest disintegration time. Specific binding agents provide easy disintegration in the gastric fluid[22-23]. The results were graphically represented in fig. 3 .

\section{Table- III: Disintegration time versus Tablet name}

\begin{tabular}{|l|l|}
\hline $\begin{array}{l}\text { Tablet } \\
\text { sample }\end{array}$ & $\begin{array}{l}\text { Disintegration time } \\
\text { (seconds) }\end{array}$ \\
\hline A & 38 \\
\hline B & 140 \\
\hline C & 50 \\
\hline D & 628 \\
\hline E & 85 \\
\hline
\end{tabular}

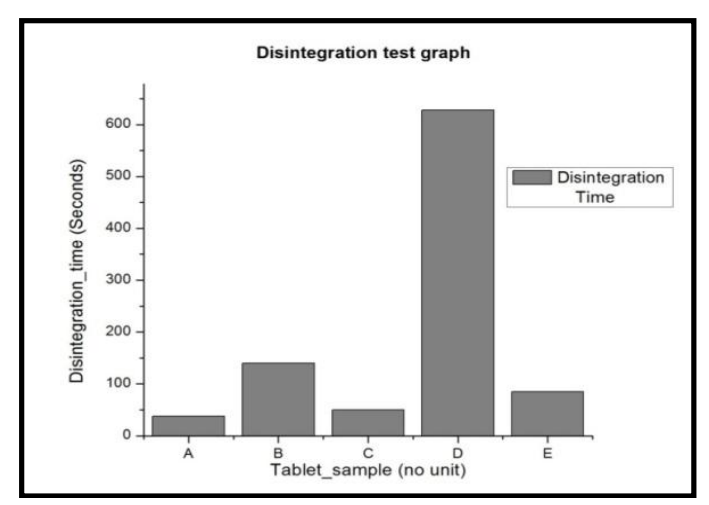

Fig. 8. Disintegration time for Tablet (name)

\section{CONCLUSION}

Corresponding FTIR, Raman and UV spectra for different tablets were recorded experimentally and compared with theoretical values. The optimized geometries, harmonic vibrational wavenumbers and intensities of vibrational bands of Acetamenophen were determined using DFT-B3LYP with $6-31+\mathrm{G}(\mathrm{d}, \mathrm{p})$ and $6-311++\mathrm{G}(\mathrm{d}, \mathrm{p})$ level calculations. The normal modes of Acetamenophenwere studied by FTIR and FT-Raman spectroscopies on the basis of $\mathrm{C}_{1}$ point group symmetry. These results will be of assistance in the quest of the experimental and theoretical evidence for acetaminophen in reaction intermediates, pharmaceuticals industries. The overall conclusions shows that the quality of the Paracetamol tablets by optical characterizations well matches experimentally and theoretically whereas the quantity analysis through weight variation, dissolution test, and disintegration time shows variation in weight and dissociation time.

\section{REFERENCES}

1. X. Zhang, L. Shan, H. Huang, X. Yang, X. Liang, A. Xing, H. Huang, X. Liu, J. Su, and W. Zhang, "Rapid identification of acetophenones in two Cynanchum species using liquid chromatography-electrospray ionization tandem mass spectrometry," J. Pharm. Biomed. Anal.,vol. 49, 2009, pp. 715-725.

2. Y.R. Prasad, A.S. Rao, and R. Rambabu, "Synthesis of some 4'-amino chalcones and their antiinflammatory and antimicrobial activity," Asian J. Chem.,vol. 21, 2009, pp.907-914.

3. P.M. Sivakumar, G. Sheshayan, and M. Doble,"Experimental and QSAR of Acetophenones as Antibacterial Agents,"Chem. Biol. Drug Des. vol. 72, 2008, pp. 303-313,

4. S.K. Seth, D.K. Hazra, Monika Mukherjee, and Tanusree Kar, "Amit $\mathrm{KN}$. Comparative in vitro dissolution assessment of some commercially available paracetamol tablets,"Int J Pharm Sci Rev Res. vol. 2(1): 2010, pp. 29-30.

5. Acetaminophen. The American Society of Health-System Pharmacists. Retrieved 3 April 2011.

6. Keith H, Derek WJ, Andrew R. Medical pharmacology and therapeutics. Philadelphia: W.B. Saunders. 2001;310

7. Acetaminophen. Chemicall and 21.com. Retrieved January 2011.

8. Viswanathan AN, Feskanich D, Schernhammer ES, Hankinson, SE Aspirin, NSAID, and Acetaminophen Use and the Risk of Endometria Cancer. Cancer Res. 2008; 68 (7): 2507.

9. Altinoz MA, Korkmaz R. NF-kappa B, macrophage migration inhibitory factor and cyclooxygenase-inhibitions as likely mechanisms behind the acetaminophen- and NSAID-prevention of the ovarian cancer Neoplasma. 2004; 51 (4): 239-47

10. Reynolds JEF. Martindale The Extra Pharmacopoeia", Pharmaceutical Press, London. 1996; 31:27-28

11. The United States Pharmacopoeia. U.S. Pharmacopeial Convention, Rockville, MD 2000, 24th revision, 17-39.

12. Banker GS. Drug Products: Their role in the treatment of disease, their quality and their status and future as drug-delivery systems In GS Banker, CT Rhodes (Eds) Modern pharmaceutics. New York: Marcel Dekker, Inc. 2002; 1-21.

13. Liya T, Esubalew A, Ayenew A. Quality evaluation of paracetamol tablets obtained from the common shops (Kiosks) in addisababa Ethiopia. Int J Pharm sci res. 2014; 5(8): 3502-3510.

14. Osama IG Khreit, Hanan AM Alkailani, Wala SK Alqathaf. A comparative study of physical and chemical parameters of selected paracetamol tablets available in the pharma market of Libya. Der PharmaChemica. 2017; 9(2):1-6.

15. Behera S, Ghanty S, Ahmad F, Santra S, Banerjee S. UV-visible spectrophotometric method development and validation of assay of paracetamol tablet formulation. J Anal Bioanal Techniques. 2012; 3:6

16. US Pharmacopoeia. The Official Compendia of Standards. 2, 2007; 1269-90.

17. Musa H, Sule YZ, Gwarzo MS. Assessment of physicochemical properties of metronidazole tablets marketed in Zaria, Nigeria. Int J Pharm Pharm Sci. 2011; 3 (Suppl 3): 27-29.

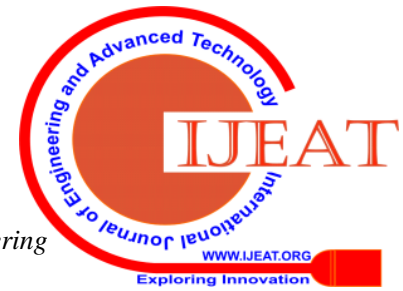




\section{Quality Analysis and Quantum Classical Analysis of Acetaminophen}

18. Ibezim EC, Attama AA, Obitte NC, Onyishi VI, Brown SA. In vitro prediction of in vivo bioavailability and bioequivalence of brands of metronidazole tablets in Eastern Nigerian drug market. Scientific Research and Essay. 2008; 3(11), 552-558.

19. Adegbolagun OA, Olalade OA, Osumah SE. Comparative evaluation of the biopharmaceutical and chemical equivalence of some commercially available brands of ciprofloxacin hydrochloride tablets. Trop J Pharm Res. 2007; 6 (3):737-745.

20. Kalakuntla R, Veerlapati U, Chepuri M, Raparla R. Effect of various super disintegrants on hardness, disinte-gration and dissolution of drug from dosage form. J AdvSci Res. 2010; 1(1): 15-19.

21. Tousey MD. Tablet pro: A tablet making training resource for tablet making professionals. Techceuticals. 2011; 4(1):1- 15.

22. C.Shende, W.Smith, C.Brouilletteand S. Farquharson, Drug Stability Analysis by Raman Spectroscopy, Pharmaceutics. 2014 Dec; 6(4): 651-662.

23. Kuldeep Delvadiya, Ritu Kimbahune, Prachi Kabra*, Sunil K, Pratik Patel, "Spectrophotometric Simultaneous Analysis Of Paracetamol, Propyphenazone And Caffeine In Tablet Dosage Forms,” Department of Quality Assurance, Nargund College of Pharmacy, Dattatreyanagar, II Main, 100 Ft. Ring Road, BSK III Stage, Bangalore560 085, India. Email: prachi.v.kabra@gmail.com Received: 01 March 2011, Revised and Accepted: 03 April 2011

\section{AUTHORS PROFILE}

Naidu Dhanpal Jayramis working as Assistant Professor in Department of physics, Kalasalingam Academy of Research and Education. His Research interests are thin films and nanomaterials. His specific area of research is development of substrates for Surface Enhanced Raman Spectroscopy. He has obtained his doctorate degree from Bharathiar University, Coimbatore, Tamil Nadu. He is a recipient of National Postdoctoral fellowship and completed Postdoc from Indian institute of science, Bangalore. He has published 9 papers in international journals and 3 papers in conferences.

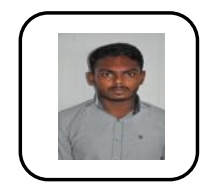

T. Santhosh has completed post graduation in department of physics,Kalasalingam Academy of Research and Education.

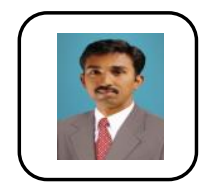

S. Jeyavijayan has completed M.Sc. and Ph.D. from Bharathidasan University, Trichirappalli in 2014 and worked as Assistant Professor in JJ College of Engineering and Technology, Trichy for 10 years Joined as Assistant Professor at Kalasalingam University from June 2015 onwards. Published more than 25 papers in National and International Journals. His fields of interest are Molecular Spectroscopy and Theoretical and Computational chemistry.

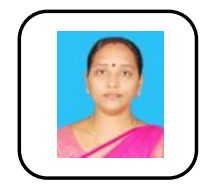

M. S. Revathy, has completed her Ph.D in Anna University in 2016. She has done M.Sc., M.Phil Physics in Mother Teresa Women's University, Kodaikanal. Currently working as Assistant Professor in Department of Physics, Kalasalingam Academy of Research and Education and her field of interests are thin films and green synthesis of nanomaterials. She has published 6 papers in international journals.

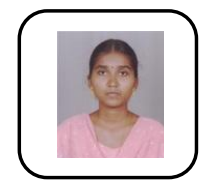

S. Soniais working as assistant professor in the Department of Physics, Holy Cross College (Autonomus), Nagercoil. She has been awarded as young scientist award and published 17 papers in national and international journals. 